\title{
Erratum to: Network Control and Engineering for QoS, Security and Mobility
}

\author{
Dominique Gaïti $^{1}$ and Nadia Boukhatem ${ }^{2}$ \\ 1 Université de Technologie Troyes, France \\ 2 ENST, France
}

\section{Erratum to:}

D. Gaïti and N. Boukhatem (Eds.)

Network Control and Engineering for QoS, Security and Mobility

DOI: $10.1007 / 978-0-387-35620-4$

The book was inadvertently published with an incorrect name of the copyright holder. The name of the copyright holder for this book is: (c) IFIP International Federation for Information Processing. The book has been updated with the changes. 